\title{
Eco-Environment Evaluation of Grassland Based on Remote Sensing Ecological Index: A Case in Hulunbuir Area, China
}

\author{
Jiawei Hui ${ }^{1}$, Zhongke Bai1,2,3*, Baoying Ye ${ }^{1,3}$ \\ ${ }^{1}$ School of Land Science and Technology, China University of Geosciences (Beijing), Beijing, China \\ ${ }^{2}$ Key Laboratory of Land Consolidation and Rehabilitation, Ministry of Natural Resources, Beijing, China \\ ${ }^{3}$ Technology Innovation Center for Ecological Restoration, Ministry of Natural Resources, Beijing, China \\ Email: *baizk@cugb.edu.cn
}

How to cite this paper: Hui, J.W., Bai, Z.K. and Ye, B.Y. (2021) Eco-Environment Evaluation of Grassland Based on Remote Sensing Ecological Index: A Case in $\mathrm{Hu}-$ lunbuir Area, China. Journal of Computer and Communications, 9, 203-213. https://doi.org/10.4236/jcc.2021.96012

Received: April 24, 2021

Accepted: June 27, 2021

Published: June 30, 2021

\begin{abstract}
This research is based on Landsat5 TM, Landsat8 OLI/TIRS remote sensing data using RSEI model to analyze and monitor the ecological environment and its temporal and spatial changes in the forest-grass transition zone in Northeast China from 2004 to 2019. The change characteristics of the ecological environment of different types of land cover types are monitored by RSEI method, and the response of different land cover types to natural factors such as precipitation and temperature is analyzed at the same time. The distribution of RSEI in the study area presents the characteristics of high in the east and low in the west. The eastern mountainous area is densely covered with woodland, which is the area with the best ecological environment quality in the study area. The grassland in the western plain and the saline-alkali land around the river are the areas with poor ecological environment in the study area. Climate, precipitation, topography and other natural elements work together to form the quality of the ecological environment in the study area roughly bounded by $120^{\circ} \mathrm{E}$. In years with poor natural conditions, this dividing line will have a clear eastward shifting trend, especially in the northern part of the study area. The spatial distribution of RSEI in the study area has a high degree of spatial autocorrelation, and Global Moran's I has been above 0.8 over the years. In terms of temporal changes in ecological conditions, the ecological environment in the study area was basically stable from 2004 to 2008, with a slight deterioration; it improved significantly from 2008 to 2011; however, it deteriorated significantly from 2011 to 2019. According to the results of partial correlation analysis, the ecological environment of the former is highly correlated with natural elements such as climate and precipitation, while the latter is mainly affected by human factors.
\end{abstract}




\section{Keywords}

RSEI, Remote Sensing, Ecological Environment, Hulunbuir

\section{Introduction}

Grassland resources are the largest ecological system on the land of China, and play an important role and value in developing animal husbandry, protecting biodiversity, maintaining water and soil, and maintaining ecological balance. At present, the ecological quality of China's grassland is facing serious risks of degradation and desertification [1] [2] [3]. Many studies have shown that overgrazing has become one of the main causes of grassland degradation [4] [5] [6] [7] [8]. From 2000 to 2012, the total amount of livestock in Hulunbuir grassland and the overload rate of livestock continued to rise, and the overload rate of livestock in 2012 exceeded 30\% [9]. In the context of the increasingly serious grazing problem in the Hulunbuir grassland area, it is necessary to evaluate and monitor the ecological conditions of the Hulunbuir grassland area. At present, the commonly used methods for grassland ecological evaluation and monitoring include NDVI change monitoring based on remote sensing data [10], vegetation change monitoring based on drone data [11], and comprehensive evaluation based on multiple data sources [12] and so on.

Remote sensing data has the characteristics of rich information, fast acquisition speed, periodicity, etc., and is widely used in the field of ecological environment monitoring (LI, 2001). Many remote sensing ecological indexes have been proposed to reflect the surface coverage and ecological quality, such as: NDVI, IBI [13], NDWI [14], SWDI [15], etc. Most of the above remote sensing indexes are extracted and studied for a single object and cannot comprehensively reflect the regional ecological environment. Some scholars have constructed a comprehensive remote sensing ecological index for a variety of objects and used multiple remote sensing ecological indicators to measure the quality of the regional ecological environment. Xu Hanqiu and others proposed a comprehensive remote sensing ecological index RSEI [16] that combines surface humidity, greenness, dryness, and temperature information. Shen Ge et al. proposed WDCI for wetland destruction [17]; Yang et al. added a parameter to measure the health of vegetation on the basis of RSEI, and proposed the CEEI index [18]. Among them, the RSEI model is widely used in regional ecological environment assessment and monitoring due to its strong comprehensiveness, simple data acquisition, and high degree of data visualization [19] [20] [21] [22].

In order to analyze the problem of the low contribution rate of the first principal component in the process, this paper adopts the RSEI model improved by Pan et al. [23] to quantitatively evaluate and monitor the characteristics of the temporal and spatial changes of the ecological environment quality in the $\mathrm{Hu}$ lunbuir grassland area, and analyze the Hulunbuir grassland. The clustering cha- 
racteristics of the ecological environment of Hulunbuir grassland area and the change characteristics of the ecological environment of different land types in the grassland area are also analyzed. At the same time, the main reasons for the changes in ecological quality are analyzed in combination with precipitation and climatic factors.

\section{Materials and Methods}

\subsection{Study Area}

The study areais located in Hulunbuir City, Inner Mongolia Autonomous Region, Northeast China. The terrain is high in the west and low in the east, with an altitude of $600-650 \mathrm{~m}$. Taking the meridian of $120^{\circ} \mathrm{E}$ as the boundary, the climate of the study area is a mid-temperate monsoon mixed forest climate to the east, and a mid-temperate monsoon forest grassland climate to the west. The climate here is characterized by large temperature difference between day and night, lack of heat, frost-free period, abundant sunshine, large difference in monthly precipitation, and precipitation is concentrated in July-August. Woodland and grassland are widely distributed in Hulunbuir City, with typical characteristics of forest-grass transition zone. Figure 1 is a schematic diagram of the ecological location and elevation of the study area.

\subsection{Data and Processing}

We selected 5 periods of remote sensing data covering the study area, including Landsat5 TM data in 2004, 2007, and 2011 and Landsat8 OLI/TIRS data in 2015 and 2019.Table 1 is the detailed information of remote sensing data. All data were download from the https://earthexplorer.usgs.gov/.

In order to use satellite radiation data to reflect surface information, remote

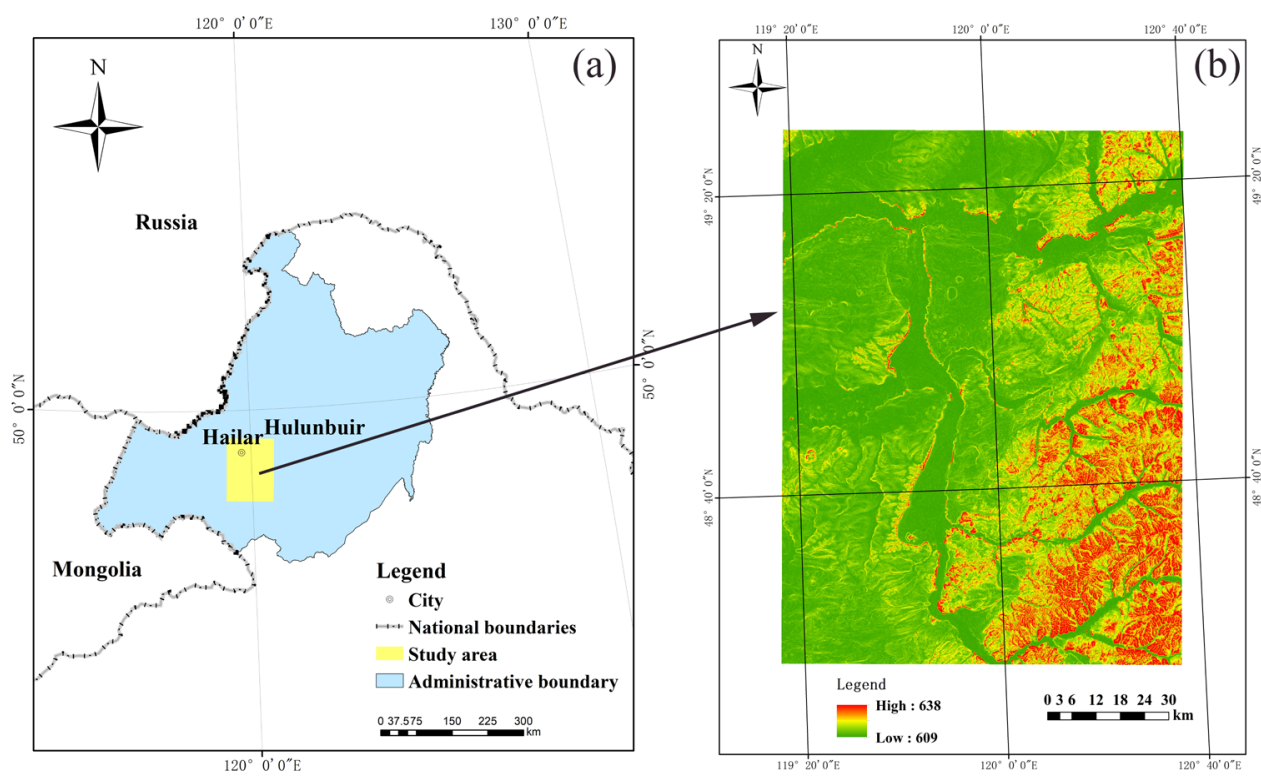

Figure 1. Study area location and elevation (a) Study area location (b) Study area elevation 
Table 1. Landsat remote sensing satellite image data from 2004 to 2019.

\begin{tabular}{cccc}
\hline Acquired date & Sensor & Path/Row & Spatial resolution \\
\hline $2004 / 8 / 23$ & TM & $123 / 026$ & $30 \mathrm{~m} / 120 \mathrm{~m}$ \\
$2008 / 9 / 3$ & TM & $123 / 026$ & $30 \mathrm{~m} / 120 \mathrm{~m}$ \\
$2011 / 8 / 11$ & TM & $123 / 026$ & $30 \mathrm{~m} / 120 \mathrm{~m}$ \\
$2015 / 7 / 5$ & OLI/TIRS & $123 / 026$ & $30 \mathrm{~m} / 100 \mathrm{~m}$ \\
$2019 / 9 / 18$ & OLI/TIRS & $123 / 026$ & $30 \mathrm{~m} / 100 \mathrm{~m}$ \\
\hline
\end{tabular}

sensing data needs to be properly processed. Using the calibration parameters provided by metadata, the image gray values of reflection and thermal bands are converted into absolute radiance. Then, the Fast Line-of sight Atmospheric Analysis of Spectral Hypercubes (FLAASH) model was used to perform atmospheric correction on the reflection and thermal bands to eliminate radiation errors caused by atmospheric influences.

\subsection{Methodology}

\subsubsection{Remote Sensing-Based Ecological Index (RSEI)}

The Remote Sensing Ecological Index (RSEI) is a comprehensive ecological evaluation index proposed by Xu Hanqiu in 2013 that is completely based on remote sensing technology, indicators to obtain, without artificially set weights, and a high degree of visualization of the results. $\mathrm{Xu}$ et al. selected four commonly used ecological elements that can reflect the quality of the ecological environment and can be retrieved by remote sensing bands, including greenness $(G)$, wetness (W), dryness (D) and temperature (T) [13].

$$
R S E I=f(G, W, D, T)
$$

Then, we selected four commonly used remote sensing ecological indexes to reflect the above ecological elements, namely The Normalized Difference Vegetation Index (NDVI), Wetness (WET), Normalized Difference Soil Index (NDSI), and Land Surface Temperature (LST). The four of them respectively represent G, W, D, T in Equation (1) Principal component analysis (PCA) is used to compress the obtained index data and extract their main information. The dimension of each index is different, so it is necessary to use min-max normalization to process the obtained data before PCA.

Combined with the situation in the study area, $\mathrm{PC}_{1}$ cannot concentrate most of the information as a result of principal component analysis, and $\mathrm{PC}_{2}$ needs to be supplemented. Using the eigenvalue contribution rate obtained by principal component analysis as the weight, $\mathrm{RSEI}_{0}$ can be calculated using $\mathrm{PC}_{1}$ and $\mathrm{PC}_{2}$ for weighted summation [23]. Then, the $\mathrm{RSEI}_{0}$ is normalized to obtain the Remote Sensing Ecological Index (RSEI), so as to classify the ecological environment. The calculation methods of NDVI, WET, NDSI, LST can be found in the references.

$$
R S E I=w_{1} P C_{1}(N D V I, W E T, N D S I, L S T)+w_{2} P C_{2}(N D V I, W E T, N D S I, L S T)
$$




\subsubsection{Spatial Autocorrelation Analysis}

Spatial autocorrelation analysis is a global spatial autocorrelation analysis of elements in space, the purpose is to judge whether the research object is cluster mode, discrete mode or random mode. Spatial autocorrelation is usually expressed by Global Moran's I. The closer its value is to 1, the stronger the spatial autocorrelation [24]:

$$
I_{g}=\frac{n}{\sum_{i} \Sigma_{j} w_{i j}}+\frac{\sum_{i} \Sigma_{j} w_{i j}\left(x_{i}-\bar{x}\right)\left(x_{j}-\bar{x}\right)}{\sum_{i}\left(x_{i}-\bar{x}\right)^{2}}
$$

where $x_{i}$ is the observation value; $w_{i j}$ is the spatial weight matrix, which is an $n^{\star} n$ symmetric matrix. When the spatial elements are adjacent, $w_{i j}$ takes 1 , and when they are not adjacent, $w_{i j}$ is 0 .

By calculating the statistically significant $\mathrm{Z}$ score (multiple of standard deviation) and $p$ value (probability), the two are judged one by one the null hypothesis, so as to decide whether to reject the null hypothesis. When $p$ is very small, it means that the observation value has a small probability of a null hypothesis, that is, it is unlikely to produce randomness.

The Local Moran Index (LISA) can effectively reflect the correlation between the quality of each ecological unit in the study area. When the global correlation is weak or absent, this tool can be used to reflect the location of the study area; when the global correlation is strong, this tool can be used to reflect the presence or absence of spatial heterogeneity [25]:

$$
I_{l}=\frac{\left(x_{i}-\bar{x}\right) \cdot \sum_{j=1}^{n} w_{i j}\left(x_{j}-\bar{x}\right)}{\sum_{i=1}^{n}\left(x_{i}-\bar{x}\right)^{2}}
$$

The meaning of each symbol is the same as equation (3).

\subsubsection{Method of Accuracy Evaluation}

We randomly sampled the RSEI data and each sub-indicator for each period 500 times, and obtained 2500 sampling points in total. The method of multiple linear regression analysis was used to evaluate the data accuracy of the 2500 sets of data to the RSEI value. The sampled value of RSEI was used as the dependent variable, and the sampled value of NDVI, WET, NDSI, and WET were used as independent variables to perform multiple linear regression analysis.

\section{Results}

\subsection{RSEI Data Accuracy Evaluation}

No independent variables are excluded in the regression analysis, indicating that the four dependent variables and independent variables all have a significant correlation.

$$
\begin{gathered}
R S E I=0.280 N D V I+0.084 W E T-0.157 N D S I-0.780 L S T+0.722 \\
R=0.963
\end{gathered}
$$

According to multiple linear regression analysis, Equation (5) is obtained. The 
results show that: RSEI has a linear correlation with the four sub-indices. Among them, NDVI, WET and RSEI are positively correlated, NDSI, LST and RSEI are negatively correlated. RSEI has a significant positive correlation with ecological environment quality.

\subsection{Analysis on the Changes of Ecological Environment Quality in the Study Area}

Table 2 shows the eigenvalues and percentages of each index in each principal component obtained after principal component analysis. The sum of the contribution rates of $\mathrm{PC} 1$ and $\mathrm{PC} 2$ can reach more than $80 \%$, which can meet the research requirements, so Pan's improved method is adopted in order to obtain more comprehensive information [23].

According to the RSEI value, the ecological environment of the study area was graded over the years. The ecological environment quality can be divided into 5 levels: Excellent, Good, Moderate, Failed, Poor. The RSEI value ranges of these levels are $[0.8,1],[0.6,0.8],[0.4,0.6],[0.2,0.4],[0,0.2]$. Figure 2 shows the spatial distribution of the ecological environment based on the above-mentioned level standards.

It can be seen from Figure 2 that the overall ecological environment quality of the study area is poor, and it has the basic characteristics of high in the east and low in the west. Lv5 and lv4 are mainly distributed in the woodlands and floodplains of the mountainous areas in the southeast. lv1 and lv2 are mainly distributed in the vast grasslands in the west and saline-alkali areas near the rivers in the middle. The boundary between the good and bad of the ecological environment is roughly around the $120^{\circ} \mathrm{E}$ meridian. In a year of good ecological environment (2011), this boundary will move to the west, otherwise it will move to the east.

Figure 3 shows the spatial distribution of the rise and fall of the ecological environment level in the study area in each period. It can be seen from Figure 3

Table 2. Partial result of principal component analysis from 2004 to 2019.

\begin{tabular}{cccccccc}
\hline \multirow{2}{*}{2004} & & NDVI & WET & NDSI & LST & Eigenvalues & Percentage \\
\hline \multirow{2}{*}{2008} & PC1 & 0.418 & 0.308 & -0.540 & -0.663 & 0.063 & $87.98 \%$ \\
& PC2 & 0.679 & 0.060 & -0.274 & 0.679 & 0.006 & $7.84 \%$ \\
& PC1 & 0.446 & 0.575 & -0.021 & -0.686 & 0.071 & $63.62 \%$ \\
\multirow{2}{*}{2011} & PC2 & -0.730 & -0.197 & -0.155 & -0.635 & 0.019 & $16.69 \%$ \\
& PC1 & 0.249 & 0.267 & -0.525 & -0.769 & 0.053 & $84.45 \%$ \\
& PC2 & 0.782 & -0.004 & -0.368 & 0.503 & 0.007 & $10.55 \%$ \\
& PC1 & 0.342 & 0.137 & -0.531 & -0.763 & 0.086 & $91.57 \%$ \\
& PC2 & -0.786 & -0.039 & 0.277 & -0.552 & 0.006 & $6.47 \%$ \\
& PC1 & 0.296 & 0.215 & -0.582 & -0.727 & 0.017 & $67.43 \%$ \\
& PC2 & -0.789 & 0.035 & 0.289 & -0.542 & 0.006 & $23.13 \%$ \\
\hline
\end{tabular}




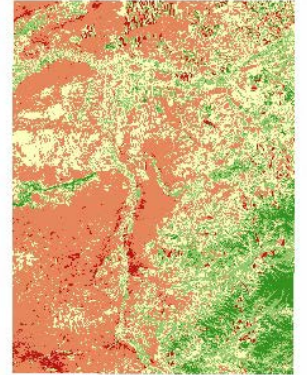

(a) 2004

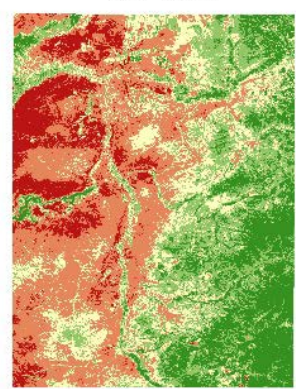

(d) 2015

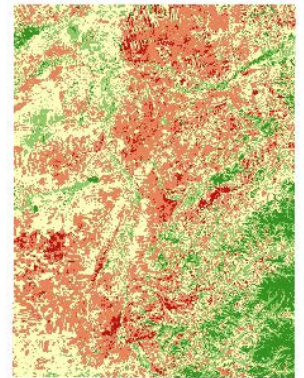

(b) 2008

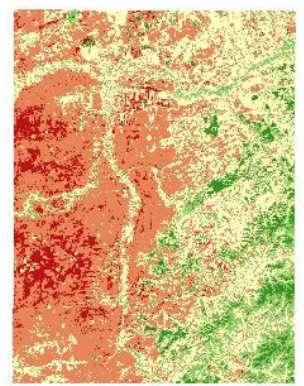

(e) 2019

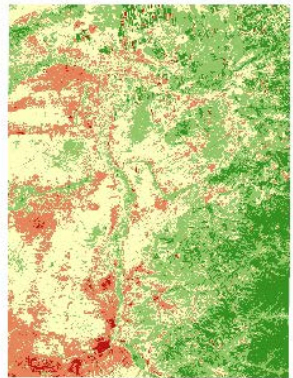

(c) 2011

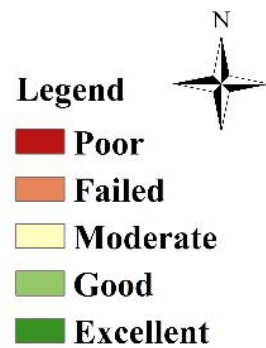

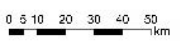

Figure 2. The spatial distribution of ecological environment levels from 2004 to 2019.

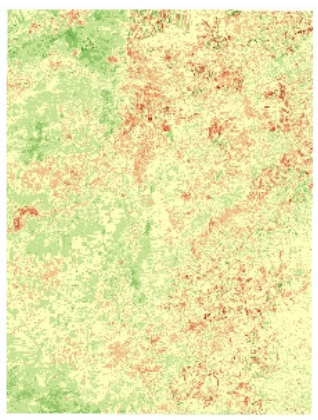

(a) $2004-2008$

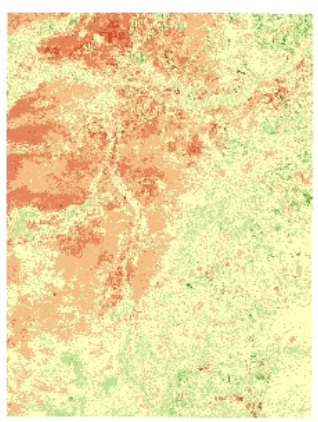

(c) 2011-2015

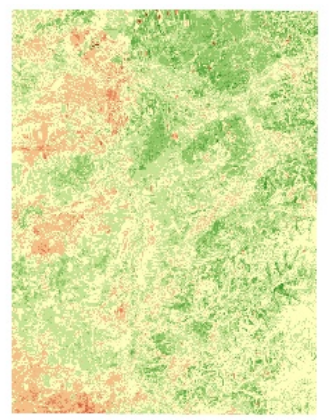

(b) $2008-2011$

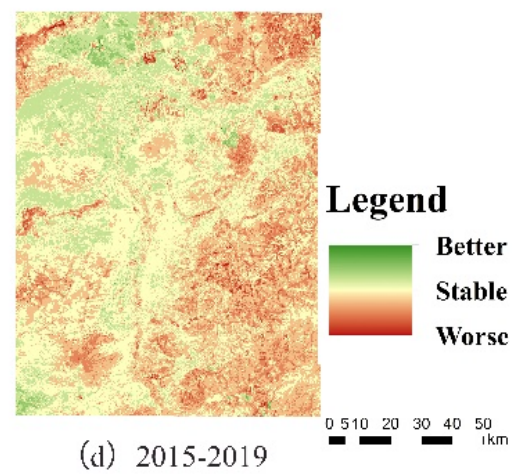

(d) $2015-2019$<smiles>CC(C)(C)N</smiles>

Figure 3. Changes in the ecological environment of the study area in each period.

that before 2015, the main areas where the ecological environment deteriorated were concentrated in the western grasslands of the study area and the cultivated land areas in the northeast, which were greatly affected by natural elements. As the ecological units with the best and worst ecological environment, floodplains 
and woodlands are areas with the most stable ecological environment. However, after 2015, large-scale deterioration of the ecological environment occurred in the woodlands in the southeast of the study area. According to high-precision remote sensing images, the main reason for the deterioration is deforestation and land reclamation.

\subsection{Spatial Autocorrelation Analysis}

In order to understand the spatial and temporal distribution pattern of the ecological environment in the study area, the study is divided into $1 \mathrm{~km}{ }^{\star} 1 \mathrm{~km}$ grids. The RSEI average value in the grid is assigned to the grid to calculate the global Moran's I of the study area (Table 3). It can be seen from the results that all the images of the 5 phases have passed this important test. From 2004 to 2019 , the $\mathrm{P}$-value is very close to 0 , and the $\mathrm{Z}$-score value is large, indicating that the RSEI distribution in the study area has a significant spatial autocorrelation. During the study period, the highest global Moran's I was in 2015 when the ecological environment was the best. The change trend of this index is consistent with the change trend of the ecological environment quality.

The above image is used to calculate the local Moran I to generate a LISA cluster map (Figure 4). There are five clustering modes in the LISA graph, which

Table 3. Landsat remote sensing satellite image data from 2004 to 2019.

\begin{tabular}{cccccc}
\hline & 2004 & 2008 & 2011 & 2015 & 2019 \\
\hline Moran's Index & 0.849 & 0.824 & 0.868 & 0.918 & 0.860 \\
z-score & 126.169 & 122.425 & 128.949 & 136.501 & 127.761 \\
p-value & 0.000 & 0.000 & 0.000 & 0.000 & 0.000
\end{tabular}

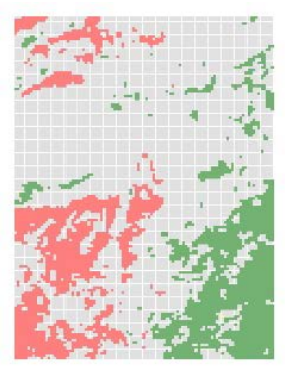

(a) 2004

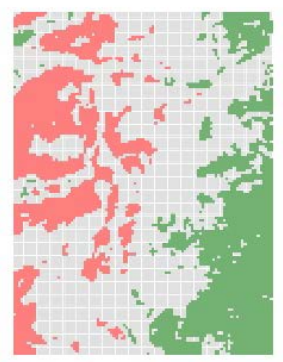

(d) 2015

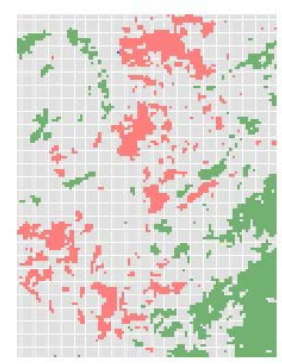

(b) 2008

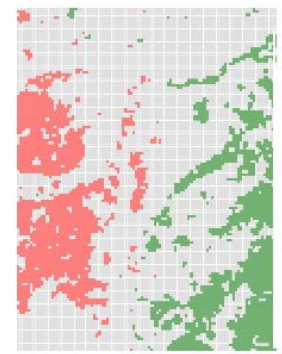

(e) 2019

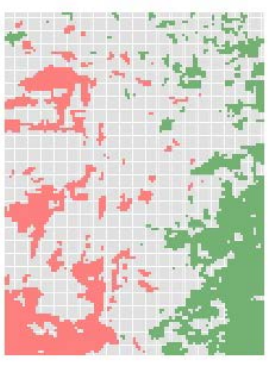

(c) 2011
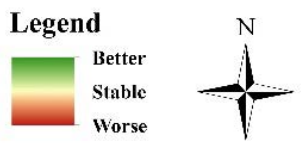

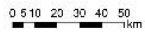

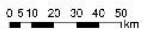

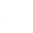

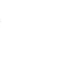

Figure 4. 2004-2019 LISA cluster map of the RSEI in the study area. 
are high-high (H-H), low-low (L-L), high-low (H-L), and low-high (L-H) and not significant. The distribution of $\mathrm{H}-\mathrm{H}$ from 2004 to 2015 was highly concentrated, but it was largely fragmented in 2019. From 2015 to 2019, a large area of forest land was destroyed by reclamation, which affected the agglomeration and integrity of high-quality ecological areas. In the years when the ecological environment is poor (2004, 2008, 2019), L-L has high agglomeration and is mainly distributed in grassland areas. In the years when the ecological environment is good $(2011,2015)$, it is mainly distributed around the river. These areas are caused by the lateral seepage of the river. Elevated groundwater level promotes salt accumulation (Fang, 2020), and a large amount of saline-alkali land is widely distributed. These saline-alkali soils often have scarce vegetation and poor ecological quality.

\section{Conclusion}

We selected the remote sensing impact of Hulunbuir grassland in 2004, 2008, 2011, 2015, and 2019, and adopted the RSEI model to quantitatively evaluate and classify its ecological environment. The results show that the ecological environment is generally high in the east and low in the west. It gradually got better before 2011, but it kept getting worse since then. The floodplain and the surrounding saline-alkali land are the areas with the most stable ecological environment quality in the study area. Then, we conducted a cluster analysis on the RSEI value of the study area, and the results showed that there is a strong spatial autocorrelation, and the deterioration of the ecological environment will have a high probability of affecting the surrounding ecological environment. RSEI can effectively show the quality of the ecological environment in the study area. In this study, the RSEI model was used to evaluate and monitor the 15-year ecological environment of the Hulunbuir grassland area, which verified a strong feasibility method for the evaluation and monitoring of the grassland ecological environment.

\section{Acknowledgements}

This research was funded by the Inner Mongolia Autonomous Region Science and Technology Major Special Project "Inner Mongolia Typical Mining Area Ecological Restoration Technology Integration and Demonstration” (2020ZD0020).

\section{Conflicts of Interest}

The authors declare no conflicts of interest regarding the publication of this paper.

\section{References}

[1] Pi, W., Du, J., Bi, Y., Gao, X. and Zhu, X. (2021) 3D-CNN Based UAV Hyperspectral Imagery for Grassland Degradation Indicator Ground Object Classification Research. Ecological Informatics, 62, Article ID: 101278. https://doi.org/10.1016/j.ecoinf.2021.101278 
[2] Nan, Z.B. (2005) The Grassland Farming System and Sustainable Agricultural Development in China. Grassland Science, 51, 15-19. https://doi.org/10.1111/j.1744-697X.2005.00003.x

[3] Zhou, W., Yang, H., Huang, L., Chen, C., Lin, X., Hu, Z. and Li, J. (2017) Grassland Degradation Remote Sensing Monitoring and Driving Factors Quantitative Assessment in China from 1982 to 2010. Ecological Indicators, 83, 303-313. https://doi.org/10.1016/j.ecolind.2017.08.019

[4] Cao, J., Adamowski, J.F., Deo, R.C., Xu, X., Gong, Y. and Feng, Q. (2019) Grassland Degradation on the Qinghai-Tibetan Plateau: Reevaluation of Causative Factors. Rangeland Ecology \& Management, 72, 988-995. https://doi.org/10.1016/j.rama.2019.06.001

[5] Martínez-Valderrama, J., Ibáñez, J., Del Barrio, G., Alcalá, F.J., Sanjuán, M.E., Ruiz, A., Hirche, A. and Puigdefábregas, J. (2018) Doomed to Collapse: Why Algerian Steppe Rangelands Are Overgrazed and Some Lessons to Help Land-Use Transitions. Science of the Total Environment, 613-614, 1489-1497. https://doi.org/10.1016/j.scitotenv.2017.07.058

[6] Fetzel, T., Petridis, P., Noll, D., Singh, S.J. and Fischer-Kowalski, M. (2018) Reaching a Socio-Ecological Tipping Point: Overgrazing on the Greek Island of Samothraki and the Role of European Agricultural Policies. Land Use Policy, 76, 21-28. https://doi.org/10.1016/j.landusepol.2018.04.042

[7] Bo, T.-L., Fu, L.-T. and Zheng, X.-J. (2013) Modeling the Impact of Overgrazing on Evolution Process of Grassland Desertification. Aeolian Research, 9, 183-189. https://doi.org/10.1016/j.aeolia.2013.01.001

[8] Du, C. and Gao, Y. (2021) Grazing Exclusion Alters Ecological Stoichiometry of Plant and Soil in Degraded Alpine Grassland. Agriculture, Ecosystems \& Environment, 308, Article ID: 107256. https://doi.org/10.1016/j.agee.2020.107256

[9] Li, M., et al. (2016) The Study on Grassland Carrying Capacity and Regulatory Approaches of Livestock-feeds Balance in Hulunbuir Grassland. Chinese Journal of Grassland, 38, 72-78.

[10] Pacheco, F.A.L., et al. (2019) Diagnosis of Degraded Pastures Using an Improved NDVI-Based Remote Sensing Approach: An Application to the Environmental Protection Area of Uberaba River Basin (Minas Gerais, Brazil). Remote Sensing Applications: Society and Environment, 14, 20-33. https://doi.org/10.1016/j.rsase.2019.02.001

[11] Zhang, J., Liu, D., Meng, B., Chen, J., Wang, X., Jiang, H., Yu, Y. and Yi, S. (2021) Using UAVs to Assess the Relationship between Alpine Meadow Bare Patches and Disturbance by Pikas in the Source Region of Yellow River on the Qinghai-Tibetan Plateau. Global Ecology and Conservation, 26, e01517. https://doi.org/10.1016/j.gecco.2021.e01517

[12] Chai, L.H. and Lha, D. (2018) A New Approach of Deriving Indicators and Comprehensive Measure for Ecological Environmental Quality Assessment. Ecological Indicators, 85, 16-728. https://doi.org/10.1016/j.ecolind.2017.11.039

[13] Xu, H. (2008) A New Index for Delineating Built-Up Land Features in Satellite Imagery. International Journal of Remote Sensing, 29, 4269-4276. https://doi.org/10.1080/01431160802039957

[14] Gao, B.C. (1996) NDWI-A Normalized Difference Water Index for Remote Sensing of Vegetation Liquid Water from Space. Remote Sensing of Environment, 58, 257-266. https://doi.org/10.1016/S0034-4257(96)00067-3

[15] Narasimhan, B. and Srinivasan, R. (2005) Development and Evaluation of Soil Mois- 
ture Deficit Index (SMDI) and Evapotranspiration Deficit Index (ETDI) for Agricultural Drought Monitoring. Agricultural and Forest Meteorology, 133, 69-88. https://doi.org/10.1016/j.agrformet.2005.07.012

[16] Xu, H., Wang, M., Shi, T., Guan, H., Fang, C. and Lin, Z. (2018) Prediction of Ecological Effects of Potential Population and Impervious Surface Increases Using a Remote Sensing Based Ecological Index (RSEI). Ecological Indicators, 93, 730-740. https://doi.org/10.1016/j.ecolind.2018.05.055

[17] Shen, G., Yang, X., Jin, Y., Xu, B. and Zhou, Q. (2019) Remote Sensing and Evaluation of the Wetland Ecological Degradation Process of the Zoige Plateau Wetland in China. Ecological Indicators, 104, 48-58.

https://doi.org/10.1016/j.ecolind.2019.04.063

[18] Yang, C., Zhang, C., Li, Q., Liu, H., Gao, W., Shi, T., Liu, X. and Wu, G. (2020) Rapid Urbanization and Policy Variation Greatly Drive Ecological Quality Evolution in Guangdong-Hong Kong-Macau Greater Bay Area of China: A Remote Sensing Perspective. Ecological Indicators, 115, 106373. https://doi.org/10.1016/j.ecolind.2020.106373

[19] Yuan, B., Fu, L., Zou, Y., Zhang, S., Chen, X., Li, F., Deng, Z. and Xie, Y. (2021) Spatiotemporal Change Detection of Ecological Quality and the Associated Affecting Factors in Dongting Lake Basin, Based on RSEI. Journal of Cleaner Production, 302, Article ID: 126995. https://doi.org/10.1016/j.jclepro.2021.126995

[20] Jing, Y., Zhang, F., He, Y., Kung, H.-T., Johnson, V.C. and Arikena, M. (2020) Assessment of Spatial and Temporal Variation of Ecological Environment Quality in Ebinur Lake Wetland National Nature Reserve, Xinjiang, China. Ecological Indicators, 110, Article ID: 105874. https://doi.org/10.1016/j.ecolind.2019.105874

[21] Boori, M.S., Choudhary, K., Paringer, R. and Kupriyanov, A. (2021) Spatiotemporal Ecological Vulnerability Analysis with Statistical Correlation Based on Satellite Remote Sensing in Samara, Russia. Journal of Environmental Management, 285, Article ID: 112138. https://doi.org/10.1016/j.jenvman.2021.112138

[22] Zheng, Z., Wu, Z., Chen, Y., Yang, Z. and Marinello, F. (2020) Exploration of EcoEnvironment and Urbanization Changes in Coastal Zones: A Case Study in China over the Past 20 Years. Ecological Indicators, 119, Article ID: 106847. https://doi.org/10.1016/j.ecolind.2020.106847

[23] Pan, Z. (2020) Study on Ecological Impact Assessment of Coal Mining based on Modify Ecological Index in Arid Desert Area of Northwest China. Master's Thesis, China University of Geosciences, Beijing. (In Chinese)

[24] Griffith, D.A. (1987) Spatial Autocorrelation. A Primer. Association of American Geographers, Washington DC.

[25] Anselin, L. (1995) Local Indicators of Spatial Association-LISA. Geographical Analysis, 27, 93-115. https://doi.org/10.1111/j.1538-4632.1995.tb00338. 